\title{
Macrophage migration inhibitory factor as an incriminating agent in vitiligo*
}

\author{
Azza Gaber Antar Farag ${ }^{1}$ \\ Mona SalahEldeen Habib ${ }^{2}$ \\ Mona Eaid Kamh ${ }^{1}$
}

\author{
Mostafa Ahmed Hammam ${ }^{1}$ \\ Nada Farag Elnaidany ${ }^{3}$
}

DOI: http:/ /dx.doi.org/10.1590/abd1806-4841.20186068

\begin{abstract}
BACKGROUND: Vitiligo is an autoimmune skin disorder in which the loss of melanocytes is mainly attributed to defective autoimmune mechanisms and, lately, there has been more emphasis on autoinflammatory mediators. Among these is the macrophage migration inhibitory factor, which is involved in many autoimmune skin diseases. However, little is known about the contribution of this factor to vitiligo vulgaris.

Овлестіvе: To determine the hypothesized role of migration inhibitory factor in vitiligo via estimation of serum migration inhibitory factor levels and migration inhibitory factor mRNA concentrations in patients with vitiligo compared with healthy controls. We also aimed to assess whether there is a relationship between the values of serum migration inhibitory factor and/ or migration inhibitory factor mRNA with disease duration, clinical type and severity in vitiligo patients.

METHODS: Evaluation of migration inhibitory factor serum level and migration inhibitory factor mRNA expression by ELISA and real-time PCR, respectively, were performed for 50 patients with different degrees of vitiligo severity and compared to 15 age- and gender-matched healthy volunteers as controls.

RESUlTs: There was a highly significant increase in serum migration inhibitory factor and migration inhibitory factor mRNA levels in vitiligo cases when compared to controls $(\mathrm{p}<0.001)$. There was a significant positive correlation between both serum migration inhibitory factor and migration inhibitory factor mRNA concentrations in vitiligo patients, and each of them with duration and severity of vitiligo. In addition, patients with generalized vitiligo have significantly elevated serum migration inhibitory factor and mRNA levels than control subjects.
\end{abstract}

STUDY LIMITATIONS: Small number of investigated subjects.

Conclusions: Migration inhibitory factor may have an active role in the development of vitiligo, and it may also be a useful index of disease severity. Consequently, migration inhibitory factor may be a new treatment target for vitiligo patients.

Keywords: Macrophage migration-inhibitory factors; RNA, messenger; Vitiligo

\section{INTRODUCTION}

Vitiligo is a common pigmentary disorder, which has profound psychological consequences and negative impact on the psychological well-being and social interactions of the patients. ${ }^{1}$ Many studies across decades and all over the world have attempted to illustrate the pathogenesis behind it; however, the pathogenesis of vitiligo remains elusive. ${ }^{2}$

Among different types of vitiligo, melanocyte loss is now widely believed to be an autoimmune process, and one of the strongest factors supporting an autoimmune origin of vitiligo vulgaris is its epidemiological association with other autoimmune diseases., ${ }^{3,4}$

Many theories have been put forward, among which the autoimmune theory is the most popular one. In addition, many studies have indicated a role for both cellular and humoral immunity in the pathogenesis of vitiligo. ${ }^{3}$

Cellular immunity is known to have a role in the pathogenesis of vitiligo. Both helper and cytotoxic $\mathrm{T}$ cells promote a T-helper (Th) 1 response with secretion of tumor necrosis factor (TNF)- $\alpha$ and interferon (IFN)- $\gamma .{ }^{5}$ Macrophage infiltration has also been found in

\footnotetext{
Received on 26.05.2016.

Approved by the Advisory Board and accepted for publication on 02.03.2017.

* Work performed at the Menoufia University - El Menoufia.

Financial support: None.

Conflict of interest: None.
Dermatology, Andrology and STDs department, Faculty of Medicine- Menoufia University - El Menoufia, Egypt.
Medical Biochemistry department, Faculty of Medicine- Menoufia University - El Menoufia, Egypt.

Clinical Pharmacy department, Faculty of Pharmacy-MSA University - $6^{\text {th }}$ October City, Egypt.
}

MAILING ADDRESS:

Azza Gaber Antar Farag

E-mail: azzagaber92@yahoo.com

(2018 by Anais Brasileiros de Dermatologia

(c)) BY-NC 
vitiligo lesions, with increased numbers present in perilesional skin. ${ }^{3}$ Macrophage migration inhibitory factor (MIF) is a critical pluripotent cytokine. It has been re-evaluated as a proinflammatory cytokine, pituitary hormone and glucocorticoid-induced immunoregulatory protein. It can exert its action by many pathways including CD74/CD44 receptor complex, CXCR4 and CXCR2. ${ }^{6} \mathrm{MIF}$ collects macrophages at inflammation sites, conversely, macrophages and $\mathrm{T}$ cells are the primary source of MIF. Extensive studies have shown that MIF has a critical role in innate and adaptive immunity. ${ }^{7,8}$

Macrophage migration inhibitory factor (MIF) is known to be involved in immune-mediated disorders, and may also play a pivotal role in many autoimmune skin diseases, such as systemic lupus erythematosus, systemic sclerosis and atopic dermatitis., ${ }^{7,9}$ Autoimmunity has a role in the etiology of vitiligo, and cellular immunity is also implicated in the pathogenesis of the disease. So, MIF may have a role in the pathogenesis of vitiligo. However, this role of MIF in vitiligo is currently not well known and only few studies investigated this issue.

Therefore, we aimed to investigate the serum levels of MIF and MIF mRNA expression in patients with vitiligo in comparison with healthy controls. We also aimed to determine whether there is any relationship between MIF serum and/or MIF mRNA levels with vitiligo duration, clinical type and severity in those patients, hoping to shed light on the hypothesized role of MIF in the etiopathogenesis of vitiligo.

\section{METHODS}

This case-control study was carried out on 50 vitiligo patients with different degrees of severity. They were selected from the Dermatology Outpatient clinic, Menoufia University hospital, between October 2014 and October 2015. In addition, 15 age- and gender-matched healthy volunteers were included as controls.

\section{Inclusion criteria:}

-Newly diagnosed cases of vitiligo.

-Any patient should stop topical (2 weeks) and systemic (1 month) treatment for his/her vitiligo before joining the study.

\section{Exclusion criteria:}

- Subjects having autoimmmune / inflammatory diseases.

- Subjects with current infection or immunosuppression.

- Pregnant or lactating women.

Each individual in the study signed a written consent form approved by The Committee of Human Rights in Research of Menoufia University.

All participants in the study were subjected to:

1-Thorough history taking, stressing on onset, duration and family history of vitiligo.

\section{2-Complete clinical examination:}

a) general examination, to detect any excluding factor

b) dermatological examination, to evaluate the vitiligo and to assess its severity based on VASI score.

3- Measurement of the serum levels of MIF protein:

From every participant, $5 \mathrm{ml}$ of venous blood were obtained in the morning between 8:00 and 9:00 am after an overnight fast, under complete aseptic condition. From those $5 \mathrm{ml}, 2 \mathrm{ml}$ were put in plain tube and allowed to clot then centrifuged at 4000 r.p.m for
$10 \mathrm{~min}$, and the separated sera were stored at $-80^{\circ} \mathrm{C}$ till timing for serologic testing. Serum level of MIF was measured using enzyme linked immunosorbant assay (ELISA) technique by Boster's human MIF ELISA Kit following the manufacturer's instructions (Boster Immunoleader, Boster Biological Technology Co., Ltd.).

4-Gene expression Analysis of Macrophage Migration Inhibitory Factor (MIF): ${ }^{10}$

RNA isolation: The other $3 \mathrm{ml}$ of the collected $5 \mathrm{ml}$ venous blood were collected in EDTA tube. Total RNA was extracted from whole blood (collected in EDTA tube) by GeneJET Whole Blood RNA Purification Mini Kit (Thermo scientific), according to the manufacturer's protocol. RNA samples were stored at -20 until analysis. The concentration of RNA was determined by measuring its absorbance at 260nm (A260). Absorbance readings should be greater than 0.15 to ensure significance. The ratio between the absorbance value at 260 and 280nm (A260 / A280) gives an estimate of RNA purity. (A260 / A280) ratio greater than 1.6 was accepted. Two-step RT-PCR was done as follows: For reverse transcription step, a reverse transcriptase kit (SensiFAST cDNA synthesis kit, Bioline Reagents Ltd, United Kingdom) was used for complementary DNA (cDNA) synthesis on 2720 thermal cycler (Singapore). For cDNA synthesis, RNA (10 $\mu$ l) was reverse transcribed in a final volume of $20 \mu \mathrm{l}$ containing $1 \mu \mathrm{l}$ of reverse transcriptase enzyme, $4 \mu \mathrm{l}$ of $5 x$ TransAmp buffer and $5 \mu l$ of DNase/RNase free water. The samples were incubated at $25^{\circ} \mathrm{C}$ for $10 \mathrm{~min}$ (primer annealing), and $42^{\circ} \mathrm{C}$ for $15 \mathrm{~min}$ (reverse transcription). Reverse transcriptase was then inactivated by heating at $85^{\circ} \mathrm{C}$ for $5 \mathrm{~min}$. All products were stored at $-20^{\circ} \mathrm{C}$ till the next step. For cDNA amplification: A relative quantitation of MIF mRNA expression normalized to the endogenous reference gene $\beta$-actin was performed by real-time reverse transcription PCR (RT-PCR), using the $2 x$ SensiFAST ${ }^{\mathrm{TM}} \mathrm{SYBR}^{\circledR}$ Lo ROX Kit (Bioline Reagents Ltd.), on Applied Biosystems 7500 Real-Time PCR System. MIF primers were: 5'-ACCAGCTCATGGCCTTCG-'3 (forward) and 5'- CTTGCTGTAGGAGCGGTT- 3' (reverse). $\beta$-actin was used as an endogenous reference with primers: $5^{\prime}$-AGTTGCGTTACACCCTTTCTTG-3' (forward) and 5' - TCACCTTCACCGTTCCAGTTT-3' (reverse). The PCR reaction mixture (final volume, 25 $\mu \mathrm{l}$ )

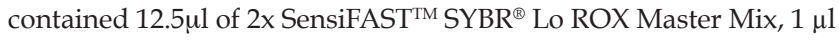
of each primer (Sigma), $5.5 \mu$ l of DNase/RNase free water and $5 \mu 1$ of cDNA. Thermocycling conditions were $10 \mathrm{~min}$ at $95^{\circ} \mathrm{C}$, followed by 45 cycles at $95^{\circ} \mathrm{C}$ for $15 \mathrm{sec}$, and $60^{\circ} \mathrm{C}$ for $1 \mathrm{~min}$. For relative quantification of the results obtained by RT-PCR; the comparative cycle threshold (Ct) method was used. Analysis was performed using Applied Biosystems7500, software version 2.0.1.The melting curves of MIF and $\beta$-actin are shown in graph 1 .

\section{Statistical analysis}

The data were collected, entered and processed on IBMPC compatible computer using SPSS software (version 20.0) (SPSS Inc., Chicago, U.S). Two types of statistics were done; the descriptive methods (for example, mean and standard deviations for normal continuous variables, median and range for non-normal continuous variables and frequencies and percentages for categorical variables) and analytic statistics: e.g. Mann Whitney $U$ test, a non-parametric test used to compare two quantitative not normally distributed. Spearman correlation test (rho) to assess correlation between two 
continuous quantitative variables not normally distributed . p-value $\leq 0.05$ was considered statistically significant.

\section{RESULTS}

\section{-Demographic and clinical data:}

This study was conducted on 50 patients with vitiligo, they were 20 males $(40 \%)$ and 30 females $(60 \%)$, with a male-to-female ratio of 2:3. Their age ranged between 5 to 70 years with $40.58 \pm 18.04$ as a mean value and 48 as a median (Table 1). Forty-one cases presented with generalized vitiligo (82\%) while 9 cases with localized vitiligo (18\%). The duration of the disease ranged between 1 month to 40 years with a mean of $12.30 \pm 10.88$ years and 10 years as a median. Family history of vitiligo was positive in 12 cases (24\%). The age of onset was from 4 to 59 years with $28.80 \pm 15.48$ as a mean and 27 as a median value. The severity of vitiligo (assessed by VASI score) ranged from 0.09 to $100 \%$ with a mean of $24.99 \pm 38.16$ and 4 as a median (Table 2). Our control group included 15 age- (range 7.0-65.0 years and a mean of $36.20 \pm 18.19$ years) and gender- ( 5 males and 10 females) matched healthy volunteers (Table 1).

MIF (serum and mRNA) levels:

Serum MIF concentrations were significantly highly elevated in patients with vitiligo vulgaris $(32.96 \pm 21.45 \mathrm{ng} / \mathrm{mL})$ compared to controls $(8.36 \pm 2.0 \mathrm{ng} / \mathrm{mL}),(\mathrm{P}<0.001)$ (Graph 2). In addition, MIF

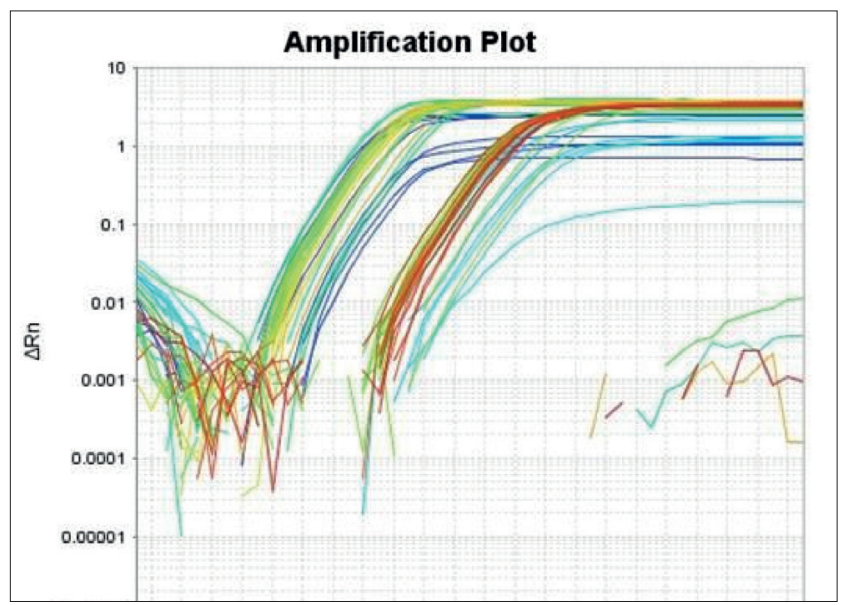

GraPH 1: Amplification plot of MIF and $\beta$-actin ( $\Delta$ Rn vs. Cycle)
mRNA levels showed also highly significant increase in vitiligo cases $(6.74 \pm 3.88 \mathrm{ng} / \mathrm{mL})$ than in the control group $(1.88 \pm 0.66 \mathrm{ng} / \mathrm{mL})$, $(\mathrm{P}<0.001)$ (Graph 2). Moreover, statistically significant positive correlation was recorded between the estimated MIF serum and MIF mRNA levels ( $r=0.48, \mathrm{p} \leq 0.001)$ (Graph 3).

Relationship between MIF serum and MIF mRNA levels with demographic and clinical criteria among vitiligo cases:

Our result revealed statistically significant correlation between both MIF serum and MIF mRNA expression levels in the studied vitiligo cases with both duration of the disease $(r=0.65, P$ $\leq 0.001$ and $\mathrm{r}=0.50, \mathrm{P} \leq 0.001$, respectively) and its severity $(\mathrm{r}=0.83$, $\mathrm{P} \leq 0.001$ for both) (Table 3 ).

The evaluated mean value of serum MIF in cases with generalized vitiligo was $(36.43 \pm 21.95)$ and in localized vitiligo cases was $(17.13 \pm 8.16)$ and this difference was considered statistically significant $(\mathrm{P}=0.01)$. Also, there was highly significant increase in MIF mRNA levels in patients with generalized $(7.45 \pm 3.88)$ than in those

TABLE 2: Clinical data of vitiligo patients

\begin{tabular}{ll} 
Items & Vitiligo patients $(\mathbf{n}=50)$ \\
\hline $\begin{array}{l}\text { Age of onset of vitiligo (years): } \\
\text { Mean } \pm \text { SD }\end{array}$ & $28.80 \pm 15.48$ \\
Median & 27.0 \\
Range & $4.0-59.0$ \\
$\begin{array}{l}\text { Duration of illness with vitiligo } \\
\text { (years): }\end{array}$ & \\
Mean \pm SD & $12.30 \pm 10.88$ \\
Median & 10.0 \\
Range & $(1$ month-40year) \\
VASI score of patients with vitiligo: & \\
Mean $\pm S D$ & $24.99 \pm 38.16$ \\
Median & 4.0 \\
Range & $0.09-100.0$ \\
Family history of vitiligo: & No $(\%)$ \\
Positive & $12(24 \%)$ \\
Negative & $38(76 \%)$ \\
Type of vitiligo: & \\
Generalized & $41(82 \%)$ \\
Localized & $9(18 \%)$ \\
\hline
\end{tabular}

\begin{tabular}{|c|c|c|c|c|c|c|}
\hline \multirow[b]{2}{*}{ Items } & \multicolumn{4}{|c|}{ Studied groups } & \multirow[b]{2}{*}{ Test of significance } & \multirow[b]{2}{*}{$\mathrm{p}$-value } \\
\hline & \multicolumn{2}{|c|}{$\begin{array}{l}\text { Vitiligo patients } \\
\qquad(\mathrm{n}=50) \\
\text { Mean } \pm \text { SD }\end{array}$} & \multicolumn{2}{|c|}{$\begin{array}{c}\text { Controls } \\
(n=15) \\
\text { Mean } \pm \text { SD }\end{array}$} & & \\
\hline Age (years): & \multicolumn{2}{|c|}{$40.58 \pm 18.04$} & \multicolumn{2}{|c|}{$36.20 \pm 18.19$} & \multirow{3}{*}{$\mathrm{t}=0.82$} & \multirow{3}{*}{$\begin{array}{c}0.41 \\
\text { NS }\end{array}$} \\
\hline Median & \multicolumn{2}{|c|}{48.0} & \multicolumn{2}{|c|}{32.0} & & \\
\hline Range & \multicolumn{2}{|c|}{$5.0-70.0$} & \multicolumn{2}{|c|}{$7.0-65.0$} & & \\
\hline Sex: & No & $\%$ & No & $\%$ & & \\
\hline Male & 20 & $40.0 \%$ & 5 & $33.3 \%$ & $\chi^{2}=0.21$ & 0.64 \\
\hline Female & 30 & $60.0 \%$ & 10 & $66.7 \%$ & & \\
\hline
\end{tabular}

$\mathrm{t}=$ Student $\mathrm{t}$ - test $\chi^{2}=$ Chi square test $\mathrm{SD}=$ Standard Deviation; $\mathrm{NS}=$ non-significant $(\mathrm{P}$-value $>0.05), \mathrm{S}=$ significant $(\mathrm{P}$-value $\leq 0.05)$ 
with localized vitiligo $(3.53 \pm 1.20)(P=0.001)$ (Table 3).

Meanwhile, both serum MIF levels and MIF mRNA concentrations are significantly increased in vitiligo cases, as well as positively correlated with vitiligo type, duration and severity. These data suggested that MIF had dynamic changes during different disease status.

However, the correlation between both MIF serum and MIF mRNA values in the studied vitiligo cases with other studied demographic and clinical data could not reach the level of significance.

\section{DISCUSSION}

In the field of dermatology, MIF- a known pro-inflammatory cytokine with a pleiotropic spectrum of biologic function- is believed to be a detrimental factor in many inflammatory dermatological diseases e.g. allergic and irritant contact dermatitis, atopic dermatitis, psoriasis, alopecia areata, pemphigus vulgaris, bullous pemphigoid, photoaging and tumorigenesis. ${ }^{11}$ The suggested role of MIF in vitiligo development is based only on two studies and its exact effect is not fully certain.

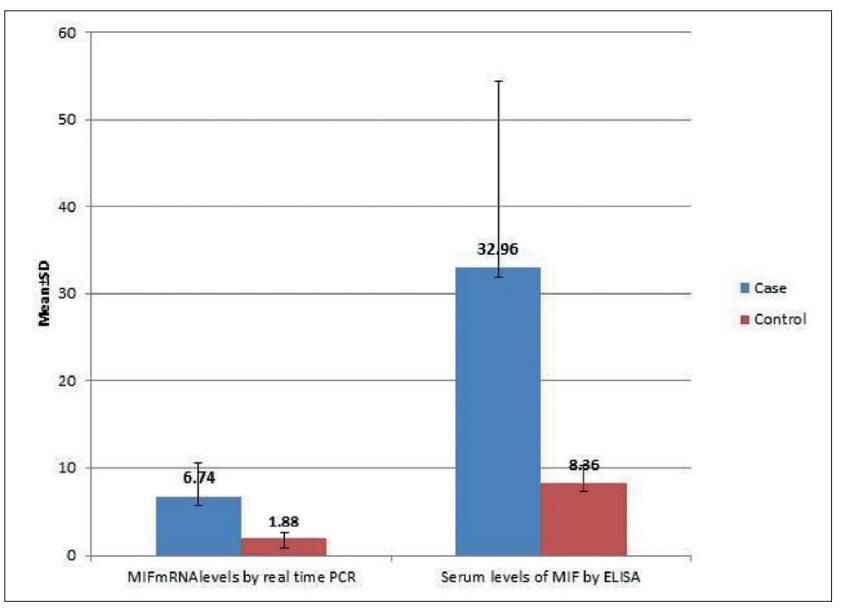

GRAPH 2: Comparison of MIF serum and MIF mRNA levels (ng/mL) between studied groups $(p<0.001)$
In the current study, we reported that in most patients with vitiligo vulgaris, MIF serum concentrations were significantly highly elevated than in control subjects, in agreement with that of Serarslan et al. ${ }^{12}$ and Ma et al. ${ }^{10}$ Within the vitiligo group, this elevated MIF serum level showed significantly positive correlation with the assessed VASI score, denoting that severe form of vitiligo is associated with high values of serum MIF. Also, estimated MIF serum levels were significantly higher in generalized than in localized vitiligo, and in long standing cases than in those of short duration of the disease.

The reported significantly positive correlations between serum MIF levels and both type and severity of vitiligo confirm the result revealed by Ma et al. ${ }^{10}$ Although Serarslan et al. agree with us regarding correlations between serum MIF levels and disease duration and type of vitiligo, they reported no association between severity of vitiligo and serum MIF levels. ${ }^{12}$ Some differences do exist in the measurement of vitiligo lesions by different evaluators and, compared with BSA scores, VASI scores include both lesional skin and the degree of depigmentation, which may be the reason for the difference between our results and those reported by Serarslan et al. ${ }^{12}$

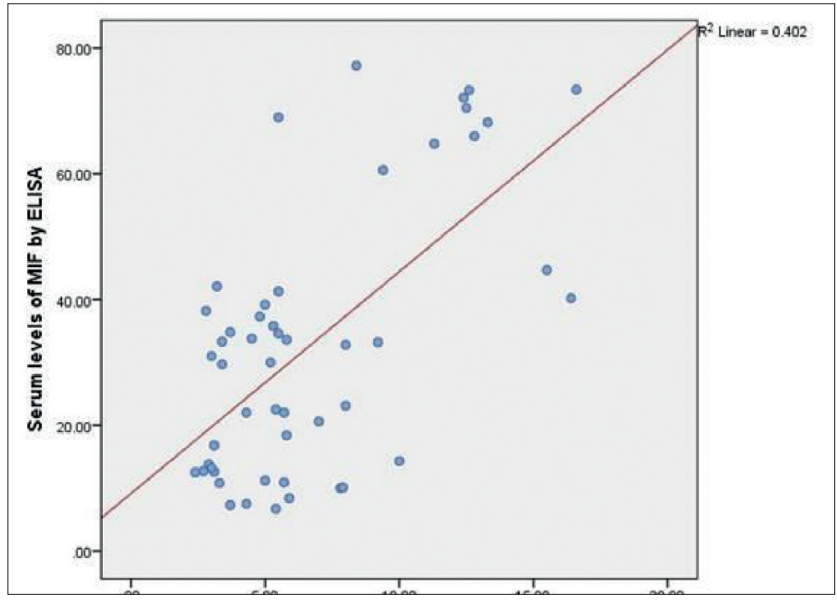

GraPH 3: Correlation between MIF mRNA levels $(\mathrm{ng} / \mathrm{mL})$ and MIF serum levels $(\mathrm{ng} / \mathrm{mL})$ in vitiligo cases $(\mathrm{r}=0.48, \mathrm{P} \leq 0.001)$

\section{TABLE 3: Relationship between MIF serum and MIF mRNA levels with personal and clinical data of vitiligo patients ( $\mathrm{n}=50$ )}

\begin{tabular}{|c|c|c|c|c|c|}
\hline Items & No. & MIF serum levels $(\mathrm{ng} / \mathrm{mL})$ Mean \pm SD & p-value & MIF mRNA levels $(\mathrm{ng} / \mathrm{mL})$ Mean \pm SD & p-value \\
\hline \multicolumn{6}{|l|}{ Gender : } \\
\hline Male & 20 & $33.86 \pm 22.60$ & $0.87^{*}$ & $7.72 \pm 4.18$ & \multirow{2}{*}{$0.10^{*}$} \\
\hline Female & 30 & $32.36 \pm 21.02$ & & $6.10 \pm 3.54$ & \\
\hline \multicolumn{6}{|l|}{ Family: } \\
\hline Positive & 12 & $34.71 \pm 22.03$ & $0.56^{*}$ & $7.40 \pm 3.88$ & \multirow{2}{*}{$0.40^{*}$} \\
\hline Negative & 38 & $32.40 \pm 21.54$ & & $6.54 \pm 3.87$ & \\
\hline \multicolumn{6}{|l|}{ Type } \\
\hline Generalized & 41 & $36.43 \pm 21.95$ & $0.01^{*}$ & $7.45 \pm 3.88$ & \multirow{2}{*}{$0.001^{*}$} \\
\hline Localized & 9 & $17.13 \pm 8.16$ & & $3.53 \pm 1.20$ & \\
\hline \multirow{2}{*}{ Age (years) } & \multirow{2}{*}{50} & $\mathrm{r}$ & $0.18^{* *}$ & $\mathrm{r}$ & \multirow{2}{*}{$0.56^{* *}$} \\
\hline & & 0.19 & & 0.08 & \\
\hline Duration (years) & 50 & 0.65 & $\leq 0.001^{* *}$ & 0.50 & $\leq 0.001^{* *}$ \\
\hline VASI score & 50 & 0.83 & $\leq 0.001^{* *}$ & 0.83 & $\leq 0.001^{* *}$ \\
\hline
\end{tabular}

** Sperman correlation $\quad$ *Mann Whitney $\mathrm{U}$ test 
In the same context, current results revealed significantly highly elevated MIF mRNA concentrations in vitiligo patients compared to volunteers, as proved, by Ma et al. ${ }^{10}$ In line with the study of Ma et al., we also reported significant high values of MIF mRNA in generalized than in localized vitiligo, and significant positive correlation between evaluated MIF mRNA and VASI score in our cases. However, the significant positive correlation between estimated MIF mRNA levels and the duration of vitiligo in our study was not reported till now. Moreover, we are the first that describe a significant correlation between both MIF serum and MIF mRNA concentrations in cases of vitiligo, that may reflect the source of serum MIF in vitiligo patients.

One particular hallmark of MIF is its ability to override immunosuppressive effects of glucocorticoids, thereby promoting and aggravating local and systemic inflammatory responses mediated by macrophages and monocytes. ${ }^{13,14}$ Furthermore, MIF up-regulates inflammatory responses by inducing the expression of other proinflammatory mediators, such as TNF- $\alpha$, nitric oxide, and prostaglandin E2, and by enhancing chemotaxis and macrophage infiltration. ${ }^{14-17}$

In vitiligo, macrophages are involved in clearing melanocytes. Macrophage infiltration has been demonstrated in vitiligo lesions and increased macrophage numbers are also observed in perilesional skin..$^{18,19}$ MIF can inhibit the random migration of macrophages, concentrate macrophages at inflammation loci and exert a variety of biological functions such as macrophage activation, enhancement of adherence, phagocytosis, and tumoricidal activity. In turn, macrophages are an important source of MIF. Thus, to some extent, it is possible that the MIF and macrophage loop may contribute to the pathogenesis of vitiligo. ${ }^{10}$

In addition, MIF is associated with the generation of cell-mediated immune responses. Accordingly, MIF has been shown to induce up-regulation of many cytokines, including IL-1 $\beta$, IL-8,
IFN- $\gamma$, TNF- $\alpha$ and IL- $6 .{ }^{20}$ TNF- $\alpha$ and IL- 6 are two inflammatory cytokines with an inhibitory effect on pigmentation. The expressions of TNF- $\alpha$ and IL- 6 mRNA levels were increased in the epidermis from vitiligo biopsies..$^{21}$ Moreover, IL-6 has been shown to play an important role in melanocytic cytotoxicity, and increased serum IL-6 levels were also detected in vitiligo vulgaris patients. ${ }^{22}$ Therefore, as a pivotal immunomodulator in the cytokine network, MIF may induce the local inflammatory and immunological responses of depigmentation associated with vitiligo vulgaris in cooperation with other cytokines.

Recently, MIF, a proinflammatory cytokine and counter-regulator of glucocorticoids, is a potential therapeutic target. Anti-MIF antibodies alleviated disease severity in mouse models of acute and chronic enterocolitis and improved, in synergy with glucocorticoids, renal function in a rat model of crescentic glomerulonephritis. The authors concluded that MIF may be a relevant target for anti-inflammatory therapy. ${ }^{23}$

\section{CONCLUSION}

Based on the above results and discussion, it could be concluded that MIF may have an active role in vitiligo development and participate in its pathogenesis, and may act as an index of disease severity. Moreover, from this piece of work, MIF may be a novel candidate that represents, in our opinion, a future therapeutic target in the pathogenesis of vitiligo.

Finally, we recommend:

1-More studies on a large scale of vitiligo patients to confirm our results.

2-Further in-depth researches to investigate the precise mechanisms by which MIF contribute to the pathogenesis of vitiligo.

3-Elegant studies for evaluation of the possible use of anti-MIF antibodies as therapeutic agents in vitiligo treatment program. 


\section{REFERENCES}

1. Osman AM, Elkordufani Y, Abdullah MA. The psychological impact of vitiligo in adult Sudanese patients. Afr J Psychiatry (Johannesbg). 2009;12:284-6.

2. Mohammed GF, Gomaa AH, Al-Dhubaibi MS. Highlights in pathogenesis of vitiligo. World J Clin Cases. 2015;3:221-30.

3. Rezaei N, Gavalas NG, Weetman AP, Kemp EH. Autoimmunity as an aetiological factor in vitiligo. J Eur Acad Dermatol Venereol. 2007;21:865-76.

4. Ingordo V, Gentile C, lannazzone SS, Cusano F, Naldi L. Vitiligo and autoimmunity: an epidemiological study in a representative sample of young Italian males. J Eur Acad Dermatol Venereol. 2011;25:105-9.

5. Passeron T, Ortonne JP. Physiopathology and genetics of vitiligo. J Autoimmun 2005;25:63-8.

6. Babu SN, Chetal G. Kumar S. Macrophage migration inhibitory factor: potential marker for cancer diagnosis and therapy. Asian Pac J Cancer Prev. 2012;13:1737-44.

7. Shimizu T. Role of macrophage migration inhibitory factor (MIF) in the skin. J Dermatol Sci. 2005;37:65-73.

8. Conroy H, Mawhinney L, Donnelly SC. Inflammation and cancer: macrophage migration inhibitory factor (MIF)-the potential missing link. QJM. 2010;103:831-6.

9. Kim JY, Kwok SK, Hur KH, Kim HJ, Kim NS, Yoo SA, et al. Up-regulated macrophage migration inhibitory factor protects apoptosis of dermal fibroblasts in patients with systemic sclerosis. Clin Exp Immunol. 2008;152:328-35

10. Ma L, Xue HB, Guan XH, Shu CM, Zhang YJ, Zhang JH, et al. Relationship of macrophage migration inhibitory factor levels in PBMCs, lesional skin and serum with disease severity and activity in vitiligo vulgaris. Braz J Med Biol Res. 2013;46:460-4.

11. Pazyar N, Feily A, Yaghoobi R. Macrophage Migration Inhibitory Factor as an Incriminating Agent in Dermatological Disorders. Indian J Dermatol. 2013:58:157.

12. Serarslan G, Yönden Z, Söğüt S, Savaş N, Celik E, Arpaci A. Macrophage migration inhibitory factor in patients with vitiligo and relationship between duration and clinical type of disease. Clin Exp Dermatol. 2010;35:487-90.

13. Calandra T, Bernhagen J, Metz CN, Spiegel LA, Bacher M, Donnelly T, et al. MIF as a glucocorticoid-induced modulator of cytokine production. Nature. 1995;377:68-71.
14. Mitchell RA, Metz CN, Peng T, Bucala R. Sustained mitogen-activated protein kinase (MAPK) and cytoplasmic phospholipase A2 activation by macrophage migration inhibitory factor (MIF). Regulatory role in cell proliferation and glucocorticoid action. J Biol Chem. 1999;274:18100-6.

15. Calandra T, Bernhagen J, Mitchell RA, Bucala R. The macrophage is an importan and previously unrecognized source of macrophage migration inhibitory factor. $J$ Exp Med. 1994;179:1895-902.

16. Bernhagen J, Calandra T, Bucala R. The emerging role of MIF in septic shock and infection. Biotherapy. 1994;8:123-7.

17. Bernhagen J, Krohn R, Lue H, Gregory JL, Zernecke A, Koenen RR, et al. MIF is a noncognate ligand of CXC chemokine receptors in inflammatory and atherogenic cell recruitment. Nat Med. 2007;13:587-96.

18. van den Wijngaard R, Wankowicz-Kalinska A, Le Poole C, Tigges B, Westerhof W, Das P. Local immune response in skin of generalized vitiligo patients. Destruction of melanocytes is associated with the prominent presence of CLA+ T cells at the perilesional site. Lab Invest. 2000;80:1299-309.

19. Le Poole IC, van den Wijngaard RM, Westerhof W, Das PK. Presence of T cells and macrophages in inflammatory vitiligo skin parallels melanocyte disappearance. Am J Pathol. 1996;148:1219-28.

20. Bucala R, Lolis E. Macrophage migration inhibitory factor: a critical component of autoimmune inflammatory diseases. Drug News Perspect. 2005;18:417-26.

21. Moretti S, Fabbri P, Baroni G, Berti S, Bani D, Berti E, et al. Keratinocyte dysfunction in vitiligo epidermis: cytokine microenvironment and correlation to keratinocyte apoptosis. Histol Histopathol. 2009;24:849-57.

22. Yu HS, Chang KL, Yu CL, Li HF, Wu MT, Wu CS, et al. Alterations in IL-6, IL-8, GM-CSF, TNF-alpha, and IFN-gamma release by peripheral mononuclear cells in patients with active vitiligo. J Invest Dermatol. 1997;108:527-9.

23. Thiele M, Kerschbaumer RJ, Tam FW, Völkel D, Douillard P, Schinagl A, et al. Selective Targeting of a Disease-Related Conformational Isoform of Macrophage Migration Inhibitory Factor Ameliorates Inflammatory Conditions. J Immunol. 2015; $195: 2343-52$

How to cite this article: Farag AGA, Hammam MA, Habib MS, Elnaidany NF, Kamh ME. Macrophage migration inhibitory factor as an incriminating agent in vitiligo. An Bras Dermatol. 2018;93(2):191-6. 